\title{
HUBUNGAN PEMURIDAN KONTEKSTUAL DI GSJA DENGAN MOTIVASI PELAYANAN PEMUDA REMAJA
}

\author{
Irawan Budi Lukmono \\ Dosen Tetap Sekolah Tinggi Teologi Gamaliel Surakarta \\ Email:
}

ABSTRACT

\section{A. PENDAHULUAN}

\section{Latar Belakang}

Salah satu tujuan dari gereja adalah memuridkan dimana gereja harus membangun sekumpulan orang-orang kudus (orang-orang percaya yang berdedikasi), mengasuh mereka menjadi serupa dengan Yesus Kristus. ${ }^{1}$ Gereja harus memiliki visi yang besar yaitu semua bangsa menjadi murid Kristus (Matius 28: 19-20). ${ }^{2}$

Tujuan dari pemuridan adalah agar setiap orang percaya dapat berakar, bertumbuh, dewasa serupa dengan Kristus (rohani, karakter, tingkah laku, perkataan, pengetahuan dan lain sebagainya) serta berbuah bagi Kristus.

Gereja Sidang Jemaat Allah Air Hidup mengembangkan pelayanan pemuridan dengan metode Kelompok Tumbuh Bersama Kontekstual. Salah satu manfaat pemuridan adalah sebagai wadah pendewasaan rohani anggota jemaat dan mendorong jemaat terlibat aktif dalam pelayanan di gereja.

Melalui penelitian ini penulis hendak menemukan hubungan antara Pemuridan Kontekstual di Gereja Sidang Jemaat Allah dengan Motivasi Pelayanan Pemuda dan Remaja.

\section{Batasan Masalah}

${ }^{1}$ Micha N.L. Tobing, Pemuridan Kelompok Keluarga Allah, (Malang: Gandum Mas, 2010), 1

${ }^{2}$ Eddy Leo, Murid Sejati: Suatu Pilihan Mutlak, (Jakarta: Metanoia, 2003), 2
Batasan masalah yang ditetapkan hanya pada permasalahan mengenai hubungan Pemuridan Kontekstual di Gereja Sidang Jemaat Allah Dengan Motivasi Pelayanan Pemuda dan Remaja. Penelitian ini ditujukan untuk pemuda dan remaja di GSJA Air Hidup pada bulan Agustus-Desember 2013.

\section{Rumusan Masalah}

Rumusan Masalah dalam penelitian ini adalah apakah ada hubungan Pemuridan Kontekstual dengan motivasi pelayanan pemuda remaja di GSJA Air Hidup?

\section{Tujuan Penelitian}

Tujuan penelitian ini adalah untuk menemukan hubungan pemuridan kontekstual dengan motivasi pelayanan pemuda remaja di GSJA Air Hidup.

\section{Manfaat Penelitian}

Manfaat penelitian ini adalah, pertama, secara teoritis, mengetahui hubungan pemuridan kontekstual dengan motivasi pelayanan pemuda dan remaja GSJA Air Hidup. Kedua, secara praktis, sebagai masukkan untuk mengembangkan pemuridan kontekstual sehingga bisa lebih baik dan dapat meningkatkan motivasi pelayanan pemuda dan remaja di GSJA Air Hidup.

\section{B. KAJIAN PUSTAKA}

\section{Pemuridan Kontekstual}

\section{Pengertian}

Pemuridan adalah proses hidup orang percaya mulai dari pengikut (follower), murid 
(disciple), sahabat (friend), sampai kepada rasul (apostle). Proses dari pengikut menuju murid dapat diartikan dengan suatu kalimat sederhana, yaitu melakukan apa yang dilakukan Yesus selaku Guru Agung. Sedangkan proses dari sahabat menuju rasul diartikan dalam satu kalimat yaitu melakukan halhal yang lebih besar daripada yang Yesus telah lakukan. ${ }^{3}$ Pemuridan adalah proses pelipatgandaan yang dinamis yang dapat menjangkau generasi penerus, bahkan berpengaruh dalam abad yang akan datang. ${ }^{4}$

\section{Dasar Alkitab Pemuridan Kontekstual}

Pemuridan Kontekstual berdasar pada Firman Tuhan yang terambil dari Matius 28: 19-20 dan Efesus 4: 11-16.

\section{Komponen-komponen dalam Pemuridan Kontekstual}

Pemuridan Kontekstual terdiri dari beberapa komponen-komponen yaitu: murid, guru, materi, metode, kurikulum dan fasilitas.

Murid adalah orang percaya yang rela dan komitmen untuk belajar dari Tuhan Yesus. Murid Kristus telah didoakan, dipanggil, dipilih, ditetapkan, diajar, diberi kuasa dan diutus oleh Tuhan Yesus ${ }^{5}$. Guru dalam pemuridan kontekstual adalah Tuhan Yesus Kristus, Roh Kudus dan orang percaya yang dikaruniai sebagai rasul, nabi, pengajar, gembala dan penginjil. Guru dalam tubuh Kristus bersifat jamak dan berfungsi sebagai fasilitator dan pengarah.

Relasi antara murid dan guru bersifat interdependensi dan menekankan persahabatan. Seperti persahabatan para murid dengan Tuhan Yesus, demikianlah relasi antara murid dengan guru dalam pemuridan kontekstual.

${ }^{3}$ Jusak Roslim, "Murid Sejati” Berkobar dalam Kristus, (Jakarta: Departemen Misi Nasional GSJA, 2010), 40

${ }^{4}$ Lydia CSES, Pemuridan: Jalan Menuju Kedewasaan Penuh Dalam Kristus (Jakarta: Empowering, Mei-Juni 2001), 11

${ }^{5}$ Matius 10: 1-16, Lukas 6: 12-13, Lukas 9:
Materi dalam pemuridan kontekstual adalah Alkitab dengan pertolongan seri bahan Kelompok Tumbuh Bersama Kontekstual yang disusun per kitab. Metode yang dipergunakan dalam pemuridan kontekstual adalah dengan Kelompok Tumbuh Bersama Kontekstual, yang berorientasi pada murid dan metode eksegesa induktif kontekstual. Metode induktif adalah metode yang berusaha menggali Firman Tuhan dengan prinsip observasi, intepretasi dan aplikasi.

Kurikulum yang ada dalam pemuridan kontekstual dirancang sesuai dengan desain Allah, sesuai kurikulum Alkitab, disusun per kitab dan disesuaikan dengan kebutuhan rohani anggota persekutuan.

Fasilitas dalam pemuridan kontekstual adalah Roh Kudus yang menjamin pertumbuhan rohani, tersedia komunitas tubuh Kristus wadah untuk bertumbuh dan tempat pemuridan yang disesuaikan dengan konteksnya.

\section{Tujuan Pemuridan Kontekstual}

Pemuridan kontekstual bertujuan agar setiap orang percaya mengalami pertumbuhan rohani serupa dengan Kristus baik dalam aspek rohani, pengetahuan, karakter, kehendak, perilaku, relasi dan pelayanannya. Tujuan ini dicapai dalam proses pembelajaran Firman Tuhan sepanjang hidup (long life learning)

\section{Metode: Melalui KTBK (Kelompok Tumbuh}

\section{Bersama Kontekstual)}

Kelompok Tumbuh Bersama Kontekstual adalah sekelompok murid Kristus terdiri dari 3-6 orang yang berkomitmen untuk bertumbuh dewasa serupa Kristus melalui: mempelajari Firman Tuhan, menaati Firman Tuhan, memiliki relasi yang saling bergantung satu dengan lainnya, dan melipatgandakan KTBK baru.

Dalam melaksanakan KTB Kontekstual, ada empat unsur yang penting, yaitu: pertama, belajar Firman Tuhan (learning). Pengajaran Firman Tuhan harus disertai kerelaan dan menaatai otoritas Firman Tuhan. Proses belajar Firman Tuhan dilakukan bersama dengan menggunakan metode induktif 
kontekstual, didukung dengan pembacaan bukubuku-buku rohani, sharing antar pribadi, diskusi tentang iman Kristen, aksi ketaatan dan lain-lainnya. Proses belajar ini dilakukan pada periode waktu tertentu sesuai dengan kesepakatan antar anggota.

Kedua, penyembahan dan doa (worship). Penyembahan merupakan respon seseorang untuk memuji dan membesarkan nama Tuhan. KTBK tidak dapat dipisahkan dengan unsur penyembahan, karena unsur ini membuat anggota KTBK lebih mengenal Allah. Penyembahan dapat dilakukan melalui doa, puji-pujian, kidung, pembacaan mazmur puji-pujian dan puisi yang berisi pujipujian. Berdoa bersama adalah cara yang khusus untuk mengutarakan beban pribadi, meminta pimpinan Tuhan dan memohon berkat-Nya. Doa menjadi wujud nyata dari kerendahan hati dan ketergantungan seseorang kepada Tuhan.

Ketiga, persekutuan (fellowship). Persekutuan kasih yang terjadi diantara anggota KTBK akan menyaksikan kepada orang lain bahwa mereka benar-benar murid Kristus (Yohanes 13: 34-35). Persekutuan dalam KTBK akan menolong semua anggota dapat saling mengasihi, melayani, membangun, memperhatikan, mensharingkan kebutuhannya masing-masing, mengakui dosadosanya, menanggung beban, membesarkan hati orang lain dan mendoakan (Efesus 4, 1 Korintus 12 dan Roma 12).

Keempat, pengutusan (mission). KTBK terkait erat dengan pengutusan. Pengutusan adalah kesaksian anggota KTBK untuk pergi memberitakan Injil Yesus Kristus kepada orang-orang yang membutuhkannya. Melalui pengutusan ini anggota KTBK dapat mempraktekkan kasih dan kuasa Allah untuk mengubah kehidupan rohani dari setiap pribadi dan masyarakat luas. Misi lain yang dilakukan setiap anggota KTBK adalah membentuk KTBK baru dengan memimpin saudara seiman lainnya yang rindu bertumbuh.

Keempat unsur ini tidak dapat dipisahkan satu sama lain, melainkan bekerja bersama-sama untuk tercapainya tujuan KTBK.

Keberhasilan KTBK selain ditentukan oleh faktor anggota, pemimpin, materi yang berkualitas dan alkitabiah, juga harus didukung oleh peranan Roh Kudus.

Roh Kudus adalah Roh Kebenaran dan guru agung bagi orang percaya. Roh Kudus akan mengingatkan dan mengajarkan Firman Kebenaran yang pernah diajarkan oleh Tuhan Yesus (Yohanes 14: 16, 25-26). Roh Kudus adalah Roh Pemimpin. Ia berkarya memimpin orang percaya kepada seluruh kebenaran (Yohanes 16: 12-18). Roh Kudus adalah saksi Kristus di dunia. Ia berkarya menyaksikan Yesus Kristus kepada dunia bersama-sama dengan orang percaya (Yohanes 15: 26-27)

Melihat pribadi Roh Kudus diatas, maka nyatalah bahwa Roh Kudus adalah pribadi yang hadir dan berperan dalam kehidupan para murid dan Firman-Nya.

Secara khusus dalam KTBK Roh Kudus menumbuhkan kerinduan dan memberikan pengertian kepada pemimpin dan anggota KTBK akan Firman Tuhan. Selain itu, Roh Kudus juga akan mengingatkan pemimpin dan anggota KTBK untuk mentaati Firman Tuhan yang telah dipelajari.

\section{Motivasi Pelayanan Remaja dan Pemuda}

\section{Motivasi Pelayanan}

Pelayanan Remaja dan Pemuda GSJA..

\section{METODOLOGI PENELITIAN}

\section{Ancangan dan Rancangan Penelitian.}

Paradigma penelitian ini adalah ancangan positivis. Penelitian positivis bersandar pada kuantifikasi dalam pengumpulan data dan analisis data untuk menguji hipotesis yang telah ditetapkan. Sesuai dengan ciri-ciri di atas penelitian ini 
menggunakan metode kuantitatif bukan eksperimental. $^{6}$

Penelitian kuantitatif ini menggunakan jenis penelitian korelasional dan deskriptif. Penelitian korelasional menjelaskan kaitan antara variabelvariabel yang telah ditentukan. Korelasional menekan-kan pola hubungan sebab akibat di antara variabel variabel, dan mencakup prediksi prilaku yang akan datang dari variabel yang akan diukur sebelum prilaku itu. Variabel yang diketahui ini untuk menentukan statistik korelasi yang akan digunakan dan untuk analisis pengujian. Dengan menggunakan kedua metode tersebut, diharapkan dapat memperoleh data yang sangat membantu peneliti dalam mengambil kesimpulan tentang hubungan antar variabel yang dikaji dalam penelitian ini. ${ }^{7}$

Penelitian ini terdiri dari dua variabel, yaitu:

1. Varabel bebas $(\mathrm{X})$ : Pemuridan Kontekstual

2. Variabel terikat (Y): Motivasi Pelayanan Remaja Pemuda

Variabel pemuridan kontekstual (X) dalam penelitian ini didefinisikan sebagai program pemuridan kontekstual dengan metode Kelompok Tumbuh Bersama Kontekstual kepada mahasiswa Kristen Fakultas Ilmu Sosial dan Ilmu Politik Universitas Sebelas Maret. Motivasi Pelayanan Mahasiswa sebagai variabel (Y) didefinisikan sebagai dorongan keterlibatan mahasiswa Kristen FISIP UNS dalam kegiatan pelayanan di kampus melalui Persekutuan Mahasiswa Kristen UNS.

Dengan demikian, kerangka berpikir dalam penelitian ini dapat dilihat dalam gambar berikut ini:

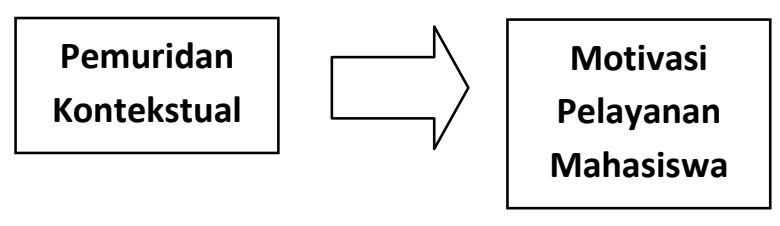

${ }^{6}$ Andreas B Subagyo, Pengantar Riset Kuantitatif dan Kualitatif (Bandung: Kalam Hidup, 2004)

${ }^{7}$ Ibid.,
Gambar 1

Variabel X mempengaruhi Variable Y

Hipotesis dalam penelitian ini adalah "Semakin baik pemuridan kontekstual yang dilaksanakan mahasiswa Kristen FISIP UNS maka semakin baik motivasi pelayanannya"

Untuk pengujian maka hipotesis di ini dideskripsikan lebih labih lanjut sebagai berikut:

Ho: Tidak korelasi antara pemuridan kontekstual mahasiswa terhadap motivasi pelayanannya.

H1: Semakin baik pemuridan kontekstual mahasiswa akan semakin baik pula motivasi pelayanannya.

Untuk mengetahui adanya Hubungan Pemuridan Kontekstual terhadap motivasi melayani, penulis menggunakan uji korelasi Rank Spearman.

Sedangkan untuk pengambilan keputusan digunakan patokan sebagai berikut:

Jika probabilitas signifikansi $(\mathrm{Sig})<0,05$ maka Ho ditolak.

Jika probabilitas signifikansi $(\mathrm{Sig})>0,05$ maka Ho diterima.

Penelitian ini dilaksanakan pada bulan Desember 2013, dengan mengambil data dari para mahasiswa Fakultas Ilmu Sosial dan Ilmu Politik Universitas Sebelas Maret yang mengikuti perkuliahan Pendidikan Agama Kristen.

\section{Populasi dan Sampel}

Populasi dan sampel dalam penelitian ini adalah mahasiswa Fakultas Ilmu Sosial dan Ilmu Politik Universitas Sebelas Maret yang mengikuti perkuliahan Pendidikan Agama Kristen sebanyak 22 mahasiswa.

Oleh karena populasi penelitian relatif sedikit maka sampel penelitian diambil sebesarbesarnya. Dalam penelitian ini sampel berjumlah 22 mahasiswa.

\section{Alat Pengumpulan Data}


Alat pengumpulan data menggunakan angket dengan skala likert. Pengukuran jawaban pertanyaan dalam angket disediakan dalam 5 (lima) tingkat jawaban, yaitu: sangat tidak setuju, tidak setuju, ragu-ragu, setuju dan sangat setuju. ${ }^{8}$

Tabel Skor dalam skala likert

\begin{tabular}{|l|l|l|}
\hline \multicolumn{2}{|l|}{ Jawaban } & $\begin{array}{l}\text { Score/ } \\
\text { Nilai }\end{array}$ \\
\hline Sangat Sesuai & SS & 4 \\
Sesuai & S & 3 \\
Tidak Sesuai & TS & 2 \\
Sangat tidak sesuai & STS & 1 \\
& & \\
\hline
\end{tabular}

\section{Uji Validitas dan Relasi Instrumen dan Normalitas Data}

Untuk mengetahui apakah alat ukur atau alat pengumpul data dapat menghasilkan data yang valid dan reliable perlu adanya uji validitas dan uji reliabilitas. Uji Validitas bertujuan untuk mengetahui apakah instrument tersebut dapat digunakan untuk mengukur apa yang hendak diukur ${ }^{9}$.

Dalam memeriksa dan memastikan validitas instrumen, peneliti menggunakan jenis validitas analisis isi (Content Validity) dan Validitas Konstruk (Contruct Validity), yakni kecocokan alat pengumpul data dengan sifat atau ciri hipotesis yang dirancang pada alat itu. ${ }^{10}$ Sedangkan untuk distribusi data dilakukan uji Normalitas.

\section{Analisis Data}

Untuk mengetahui ada tidaknya hubungan pemuridan kontekstual terhadap motivasi melayani, digunakan uji korelasi Rank Spearman dengan rumus:

${ }^{8}$ Andreas B Subagyo, Pengantar Riset Kuantitatif dn Kualitatif (Bandung: Kalam Hidup, 2004),

${ }^{9}$ Sugiyono, Statistika Untuk Penelitian (Bandung: Alfabeta, 2007), 348.

${ }^{10}$ Subagyo, 233.

$$
\begin{gathered}
\rho=1-\frac{6 \sum D i^{2}}{n\left(n^{2}-1\right)} \\
r_{s}=\frac{\sum x^{2}+\sum y^{2}-\sum d^{2}}{2 \sqrt{\sum x^{2} \sum y^{2}}}
\end{gathered}
$$

Analisis data dengan pertolongan program Excel.

\section{HASIL PENELITIAN}

Hasil analisis korelasi Spearman's rho (rs) antara hubungan pemuridan kontekstual terhadap motivasi melayani adalah sebagai berikut:

TABEL KORELASI RANK SPEARMAN

\begin{tabular}{|c|c|c|c|c|c|c|c|c|c|}
\hline No & $\mathrm{Xi}$ & $\mathrm{Yi}$ & $\mathrm{Rx}$ & $\mathrm{Ry}$ & $\begin{array}{c}\mathrm{Rx} \\
\mathrm{Ry}\end{array}$ & $\mathrm{Rx}{ }^{2}$ & $\mathrm{Ry}{ }^{2}$ & $\mathrm{Di}$ & $\mathrm{Di}^{2}$ \\
\hline 1 & 40 & 48 & 2 & 3 & 6 & 4 & 9 & -1 & 1 \\
\hline 2 & 48 & 47 & 7 & 2 & 14 & 49 & 4 & 5 & 25 \\
\hline 3 & 49 & 52 & 8 & 5 & 40 & 64 & 25 & 3 & 9 \\
\hline 4 & 39 & 48 & 1 & 3 & 3 & 1 & 9 & -2 & 4 \\
\hline 5 & 59 & 53 & 13 & 6 & 78 & 169 & 36 & 7 & 49 \\
\hline 6 & 50 & 47 & 9 & 2 & 18 & 81 & 4 & 7 & 49 \\
\hline 7 & 49 & 55 & 8 & 7 & 56 & 64 & 49 & 1 & 1 \\
\hline 8 & 45 & 48 & 5 & 3 & 15 & 25 & 9 & 2 & 4 \\
\hline 9 & 43 & 50 & 4 & 4 & 16 & 16 & 16 & 0 & 0 \\
\hline 10 & 48 & 48 & 7 & 3 & 21 & 49 & 9 & 4 & 16 \\
\hline 11 & 43 & 48 & 4 & 3 & 12 & 16 & 9 & 1 & 1 \\
\hline 12 & 45 & 50 & 5 & 4 & 20 & 25 & 16 & 1 & 1 \\
\hline 13 & 42 & 48 & 3 & 3 & 9 & 9 & 9 & 0 & 0 \\
\hline 14 & 51 & 47 & 10 & 2 & 20 & 100 & 4 & 8 & 64 \\
\hline 15 & 52 & 56 & 11 & 8 & 88 & 121 & 64 & 3 & 9 \\
\hline 16 & 43 & 50 & 4 & 4 & 16 & 16 & 16 & 0 & 0 \\
\hline 17 & 47 & 44 & 6 & 1 & 6 & 36 & 1 & 5 & 25 \\
\hline 18 & 54 & 50 & 12 & 4 & 48 & 144 & 16 & 8 & 64 \\
\hline & & 5 & & & 486 & 989 & 305 & & 322 \\
\hline
\end{tabular}

Diketahui

\begin{tabular}{|l|l|l|l|}
\hline$\sum \mathrm{Di}^{2}$ & 322 & $\sum \mathrm{X}^{2}$ & 481 \\
\hline
\end{tabular}




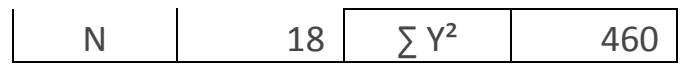

Jadi,

Rs $=0,65797$

Berdasarkan hasil analisa data di atas ternyata koefisien korelasi ( $\mathrm{rs}$ ) $=0,658$ (kuat dan positif). Artinya ada hubungan yang positif dan kuat antara pemuridan kontekstual dengan motivasi melayaninya.

\section{E. KESIMPULAN}

Dari penelitian ini disimpulkan bahwa semakin baik pemuridan kontekstual mahasiswa Kristen FISIP UNS maka semakin baik pula motivasi melayaninya.

\section{DAFTAR KEPUSTAKAAN}

Heath, W.S, Tak Mengambang Tak Meleset Yogyakarta: Andi Offset, 2000

Christenson, Evelyn, Berubah: Pola Hidup Ilahi Malang: Gandum Mas, 1989.

Packer, JI, Apakah Saudara Memerlukan Perubahan Kepribadian?: Pola Hidup Ilahi, Malang: Gandum Mas, 1989.

Subagyo, Andreas B, Pengantar Riset Kuantitatif dan Kualitatif, Bandung: Kalam Hidup, 2004

Sugiyono, Statistika Untuk Penelitian (Bandung: Alfabeta, 2007 